\title{
2D transition metal carbides (MXenes) in metal and ceramic matrix composites
}

\author{
Brian C. Wyatt ${ }^{1,2+}$, Srinivasa Kartik Nemani ${ }^{1,2+}$ and Babak Anasori ${ }^{1,2^{*}}$ (i)
}

\begin{abstract}
Two-dimensional transition metal carbides, nitrides, and carbonitrides (known as MXenes) have evolved as competitive materials and fillers for developing composites and hybrids for applications ranging from catalysis, energy storage, selective ion filtration, electromagnetic wave attenuation, and electronic/piezoelectric behavior. MXenes' incorporation into metal matrix and ceramic matrix composites is a growing field with significant potential due to their impressive mechanical, electrical, and chemical behavior. With about 50 synthesized MXene compositions, the degree of control over their composition and structure paired with their high-temperature stability is unique in the field of 2D materials. As a result, MXenes offer a new avenue for application driven design of functional and structural composites with tailorable mechanical, electrical, and thermochemical properties. In this article, we review recent developments for use of MXenes in metal and ceramic composites and provide an outlook for future research in this field.
\end{abstract}

Keywords: MXenes, Nanomaterials, Composites, Metals, Ceramics, Mechanical, High-temperature

\section{Introduction}

Two-dimensional (2D) nanomaterials have been under great demand as reinforcing and property tailoring materials in composite applications due to their in-plane mechanical stiffness and strength $[1,2]$, high chemical activity [3-5], as well as their capacitive and conductive properties [6-8]. 2D MXenes (possible structures of MXenes and their elements are shown in Fig. 1a), have renewed interest to meet this demand due to their impressive mechanical stiffness (up to $386 \pm 13 \mathrm{GPa}$ for $\mathrm{Nb}_{4} \mathrm{C}_{3} \mathrm{~T}_{x}$ ) (Fig. 1b) [9], catalytic potential [10], and high in-plane electrical conductivity (up to $20,000 \mathrm{~S} \mathrm{~cm}^{-1}$ for $\mathrm{Ti}_{3} \mathrm{C}_{2} \mathrm{~T}_{x}$ ) (Fig. 1c) [11]. MXenes are 2D transition metal carbides and nitrides that are denoted by a chemical formula of $\mathrm{M}_{n+1} \mathrm{X}_{n} \mathrm{~T}_{x}$ ( $n=1$ to 4 ), where $\mathrm{M}$ represents $3 d-5 d$ block transition metals (groups 3-6 of the periodic table) layers which are interleaved by $\mathrm{X}$ layers, where $\mathrm{X}$ represents carbon or nitrogen [12]. In addition,

\footnotetext{
*Correspondence: banasori@iupui.edu

†Brian C. Wyatt and Srinivasa Kartik Nemani contributed equally

${ }^{2}$ Integrated Nanosystems Development Institute, Indiana University-

Purdue University Indianapolis, IN 46202 Indianapolis, USA

Full list of author information is available at the end of the article
}

$\mathrm{T}_{x}$ represents surface terminations bonded to the outer $M$ layers of MXenes, where $T_{x}$ are generally a mixture of $-\mathrm{O},-\mathrm{F},-(\mathrm{OH})$, or $-\mathrm{Cl}$ surface groups [12]. MXenes are derived from their carbide precursors (mostly MAX phases). In a MAX phase formula, $M$ and $X$ represent the same elements as MXene while A represents A-group elements, which are commonly from groups 13-16 of the periodic Table [13]. MXenes are synthesized through selective removal of the A-layers in MAX through chemical etching in either aqueous hydrofluoric acid [14-16] or molten salt etchants [17], where the nature and the concentration of the etchants significantly influences the surface functional groups on the resultant MXene structure $[18,19]$. The wide array of compositional, structural, and processing choices for MXene permits application-driven design of these nanomaterials to develop a wide array of behaviors [12, 20-22].

MXenes' impressive properties have led to their inclusion in nanocomposites, which have been implemented in energy-related applications such as supercapacitors [23-25], battery electrodes [26-28], and active catalytic materials [29-31]. In these nanocomposites, MXenes are advantageous additive materials due to a combination of 

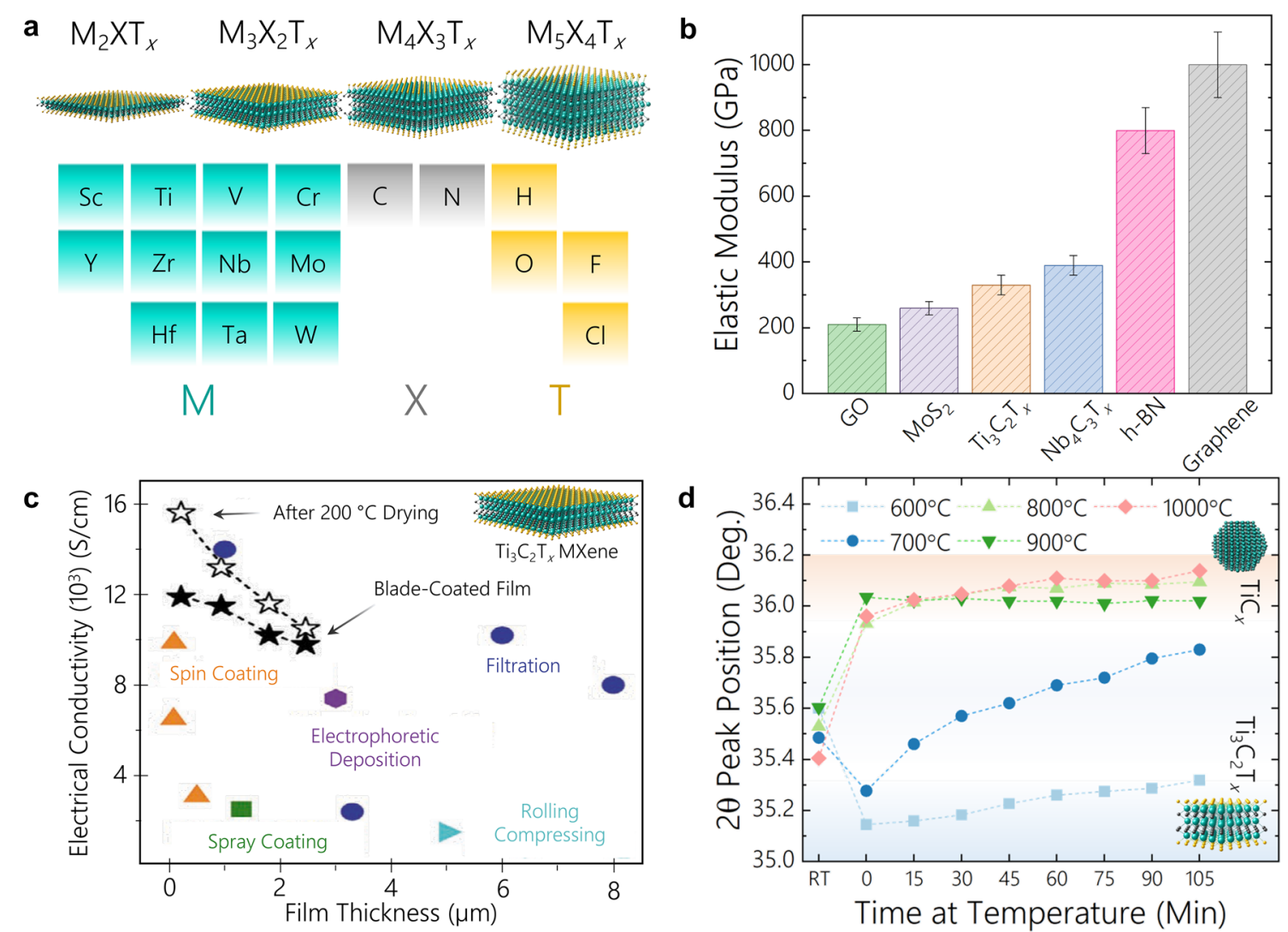

Fig. 1 2D MXenes wide array of possible compositions, and impressive mechanical, electrical, and high-temperature properties. a MXenes can be comprised of transition metals of groups 3-6 of the periodic table with carbon or nitrogen and are surrounded by mixed surface groups, of which are commonly $-\mathrm{O},-\mathrm{F},-(\mathrm{OH})$, and $-\mathrm{Cl}$. b MXenes have shown the highest mechanical stiffness of all solution processable nanomaterials $[9$, 21]. $\mathbf{c} \mathrm{Ti}_{3} \mathrm{C}_{2} \mathrm{~T}_{x} \mathrm{MXenes}$ have shown exceptionally high electrical conductivity depending on the synthesis and fabrication techniques [41]. $\mathbf{d} \mathrm{Ti}_{3} \mathrm{C}_{2} \mathrm{~T}_{x}$ MXenes have shown phase transitions to its highly stable $\mathrm{TiC}_{\mathrm{y}}$ form at temperatures ranging from $700-1000^{\circ} \mathrm{C}[40]$

high electrical conductivity, high electrochemical activity, and strong chemical affinity toward oppositely charged species, which assists in active binding [10,32, 33]. This remarkable behavior of MXenes is also seen in polymer composites, where MXenes add mechanical reinforcement and electrical conductivity while permitting tailorable chemical activity ranging from selective ion sieving, EM wave attenuation, flame retardancy, catalytic activity, and tribological behavior improvement [34].

Similar to these previous successes of MXenes in nanocomposites due to MXenes' inherent material properties, MXenes have shown potential as functional fillers in metal matrix composites (MMCs) and ceramic matrix composites (CMCs). In addition to MXenes' noteworthy mechanical and electrical behavior, their high surface charge in a range of solvents [25, 35] permits exploration of solution-based mixing processes. Overall, the strong mechanical properties of MXenes $(330 \pm 30 \mathrm{GPa}$ and $386 \pm 13 \mathrm{GPa}$ for $\mathrm{Ti}_{3} \mathrm{C}_{2} \mathrm{~T}_{x}$ and $\mathrm{Nb}_{4} \mathrm{C}_{3} \mathrm{~T}_{x}$, respectively) $[9,36]$ make MXenes the stiffest solution-processable
2D nanomaterials to date (Fig. 1b), which illustrates MXenes' promise for solution mixing methods. In addition, MXenes inner transition metal carbide/nitride core allows them to be used as a stable high-temperature reinforcement material [37-40]. Although MXenes 1-nmthick flakes (for $\mathrm{M}_{3} \mathrm{X}_{2} \mathrm{~T}_{x}$ structures) are prone to oxidation in air or aqueous media, MXenes are stable high-temperature phases in dry and oxygen-free environments, such as in encapsulation with metal or ceramic matrices, to meet the greater structural and chemical stability demanded in high-temperature applications.

This high-temperature behavior of MXene flakes in a controlled environment may be categorized in two regimes. First, surface groups are desorbed from the MXenes' surface in sequential order [37]. For example, $\mathrm{Ti}_{3} \mathrm{C}_{2} \mathrm{~T}_{x}$ with $\mathrm{T}_{x}$ : $-\mathrm{O},-\mathrm{F}$, and $-(\mathrm{OH})$ under high-temperature annealing will lose its surface groups starting with the $-\mathrm{OH}$ groups at temperatures of $300-500{ }^{\circ} \mathrm{C}$, followed by $-\mathrm{F}$ groups around $500-750{ }^{\circ} \mathrm{C}$, subsequently with complete removal of surface groups above $800{ }^{\circ} \mathrm{C}$ 
[37-39]. Second, annealing temperatures above this point are accompanied by phase transitions of MXene to $\mathrm{TiC}_{y}$ superstructures. Previously, we have reported that $\mathrm{Ti}_{3} \mathrm{C}_{2} \mathrm{~T}_{x}$ MXene will transform to two forms of 3D crystalline nonstoichiometric $\mathrm{TiC}$ at temperatures higher than $700{ }^{\circ} \mathrm{C}$. These phase transformations of $\mathrm{Ti}_{3} \mathrm{C}_{2} \mathrm{~T}_{x}$ MXene at temperatures above $700{ }^{\circ} \mathrm{C}$ and below $1000{ }^{\circ} \mathrm{C}$ result in formation of cubic $\mathrm{TiC}_{y}(0.5<y<1.0)$ in an ordered vacancy cubic superstructure of $\mathrm{Ti}_{2} \mathrm{C}$ (only $\mathrm{TiC}_{y}$ is shown in Fig. 1d for visual simplicity) [40]. At these annealing temperatures, all three phases of $\mathrm{Ti}_{3} \mathrm{C}_{2} \mathrm{~T}_{x}, \mathrm{Ti}_{2} \mathrm{C}$, and $\mathrm{TiC}_{y}$ occupy the layered $\mathrm{Ti}-\mathrm{C}$ structure simultaneously up to $1000^{\circ} \mathrm{C}[40]$. At temperatures above $1000^{\circ} \mathrm{C}$, the structure transforms to cubic $\mathrm{TiC}_{y}$ with disordered carbon vacancies. When single-flake $\mathrm{Ti}_{3} \mathrm{C}_{2} \mathrm{~T}_{x}$ MXene is used as the starting material, the cubic $\mathrm{TiC}_{y}$ maintains the layered nature of MXene flakes and transforms in a lamellar morphology [40]. The structural stability of $\mathrm{Ti}_{3} \mathrm{C}_{2} \mathrm{~T}_{x}$ MXenes in their hexagonal crystal lattice up to $700{ }^{\circ} \mathrm{C}$ and their similar phase integrity for lamellar transition metal carbide/nitride structures at temperatures higher than $1000{ }^{\circ} \mathrm{C}$ illustrates MXenes' promise as a stable 2D nanomaterial and lamellar structures for hightemperature composite materials. The combination of MXenes' phase stability paired with its aforementioned impressive mechanical and electrical behaviors lend significant promise for MXenes as reinforcement nanomaterials for the next-generation of metal and ceramic matrix composites.

\section{MXenes metal matrix composites (MMCs)}

MXenes' strong $\mathrm{M}-\mathrm{X}$ interior paired with their abundant surface terminations make them a compatible candidate material for use in metal matrix composites for structural and tribological applications. Recent studies have investigated $\mathrm{Ti}_{3} \mathrm{C}_{2} \mathrm{~T}_{x}$ MXene as a reinforcement material for $\mathrm{Al}$ via powder metallurgy processes [42-44], as shown in Fig. 2a. The first of these mechanical studies on MXene/ $\mathrm{Al}$ composites mixed non-delaminated multilayer $\mathrm{Ti}_{3} \mathrm{C}_{2} \mathrm{~T}_{x}$ powder and $\mathrm{Al}$ powder via ball milling followed by pressureless sintering at $650^{\circ} \mathrm{C}$ in an Ar environment, which was further followed by hot rolling [43]. Another study used delaminated few-layer flakes of $\mathrm{Ti}_{3} \mathrm{C}_{2} \mathrm{~T}_{x}$ in $\mathrm{Al}$ powder mixed in water under sonication, which was followed by spark plasma sintering (SPS) at $580{ }^{\circ} \mathrm{C}$ for 20 min under $50 \mathrm{MPa}$ and further followed by hot extrusion [44]. The use of up to $3 \mathrm{wt} \%$ non-delaminated $\mathrm{Ti}_{3} \mathrm{C}_{2} \mathrm{~T}_{x}$ powder mixed in $\mathrm{Al}$ resulted in a tensile strength improvement of $50 \%$ [42] while the few-layer delaminated $\mathrm{Ti}_{3} \mathrm{C}_{2} \mathrm{~T}_{x}$ achieved a tensile strength improvement of $66 \%$ at only $0.2 \mathrm{wt} \%$ inclusion of $\mathrm{Ti}_{3} \mathrm{C}_{2} \mathrm{~T}_{x}$ in $\mathrm{Al}$ [44].

In addition, studies on non-delaminated MXene in $\mathrm{Cu}$ matrices for mechanical strength have been investigated.
One study utilized an ethanol solution-based mixing method of non-delaminated multilayer $\mathrm{Ti}_{3} \mathrm{C}_{2} \mathrm{~T}_{x}$ powder with a $\mathrm{Cu}$ precursor using reductive heat treatment at $60{ }^{\circ} \mathrm{C}$ to yield $\mathrm{Cu}$ followed by SPS at $800^{\circ} \mathrm{C}$ under $35 \mathrm{MPa}$ for $5 \mathrm{~min}$ with a temperature ramp rate of $50^{\circ} \mathrm{C} / \mathrm{min}$ [45]. Another study on non-delaminated $\mathrm{Ti}_{3} \mathrm{C}_{2} \mathrm{~T}_{x}$ powder in $\mathrm{Cu}$ matrices used high-energy ball milling at $350 \mathrm{RPM}$ in Ar to mix the $\mathrm{Cu}$ and $\mathrm{Ti}_{3} \mathrm{C}_{2} \mathrm{~T}_{x}$ powders followed by vacuum hot pressing at $1040{ }^{\circ} \mathrm{C}$ and $25 \mathrm{MPa}$ for $30 \mathrm{~min}$ with a temperature ramp rate of $1.5^{\circ} \mathrm{C} / \mathrm{min}$ to sinter the samples [46]. These studies showed non-delaminated $\mathrm{Ti}_{3} \mathrm{C}_{2} \mathrm{~T}_{x}$ powder mechanically reinforced the $\mathrm{Cu}$ matrix, with a reported improvement up to $50 \%$ over the pure $\mathrm{Cu}$ matrix $[45,46]$. While these studies on $\mathrm{Al}$ and $\mathrm{Cu}$ matrices did not use identical processing conditions, the use of delaminated few-layer $\mathrm{Ti}_{3} \mathrm{C}_{2} \mathrm{~T}_{x}$ MXene is expected to be significantly more effective in improving the mechanical properties compare with multilayer $\mathrm{Ti}_{3} \mathrm{C}_{2} \mathrm{~T}_{x}$ powder.

In general, the more effective strengthening of singleflake MXene over its multilayer powder counterpart is likely due to the increased surface area for stress transfer from the metal matrix to the delaminated MXene 2D flakes. This increase in surface area has shown to be a very important factor in previous studies of $2 \mathrm{D}$ nanomaterial reinforced metal matrix composites [47]. Additionally, the interaction between MXene flakes in a multilayer MXene particle is secondary bonding (e.g., the inter-flake bonding is van der Waals) which is weaker than the primary in-plane $\mathrm{M}-\mathrm{X}$ bonding. The use of single-flake MXenes will ensure that the MXene materials only have primary bonding as the reinforcing material, which can lead to larger improvements in mechanical properties. The significant improvement in strengthening efficiency of single-flake $\mathrm{Ti}_{3} \mathrm{C}_{2} \mathrm{~T}_{x}$ sheets in $\mathrm{Al}$ composites as compared to graphene nanoplatelets (GPLs), carbon nanotubes (CNTs), carbon nanofibers (CNFs), and ceramic and refractory particles is shown in Fig. 2b [42]. This graph shows MXene's potential to improve the mechanical properties of metal composites as compared to competitive reinforcement materials.

Delaminated single-flake $\mathrm{Ti}_{3} \mathrm{C}_{2} \mathrm{~T}_{x}$ MXene have also been investigated as an additive material to $\mathrm{Mg}$ - $\mathrm{Li}$ composites. $\mathrm{Ti}_{3} \mathrm{C}_{2} \mathrm{~T}_{x}$ Mg-Li MMCs have been fabricated via a molten-gelation mixing process with $\mathrm{Ti}_{3} \mathrm{C}_{2} \mathrm{~T}_{x}$ incorporated into in the molten metal via sonication in temperatures exceeding $500{ }^{\circ} \mathrm{C}$, as shown in Fig. 2c [48]. This process has resulted in a tensile yield strength improvement of $128 \%$ over the matrix metal [48]. Partial phase transformation of $\mathrm{Ti}_{3} \mathrm{C}_{2} \mathrm{~T}_{x}$ was noted with a 3 times increase in flake thickness and identification of mixed hexagonal and cubic phases in the recovered flakes [48]. These changes could potentially illustrate partial phase transformations of $\mathrm{Ti}_{3} \mathrm{C}_{2} \mathrm{~T}_{x}$ to mixed $\mathrm{Ti}_{2} \mathrm{C}$ and $\mathrm{TiC}_{y}$ 

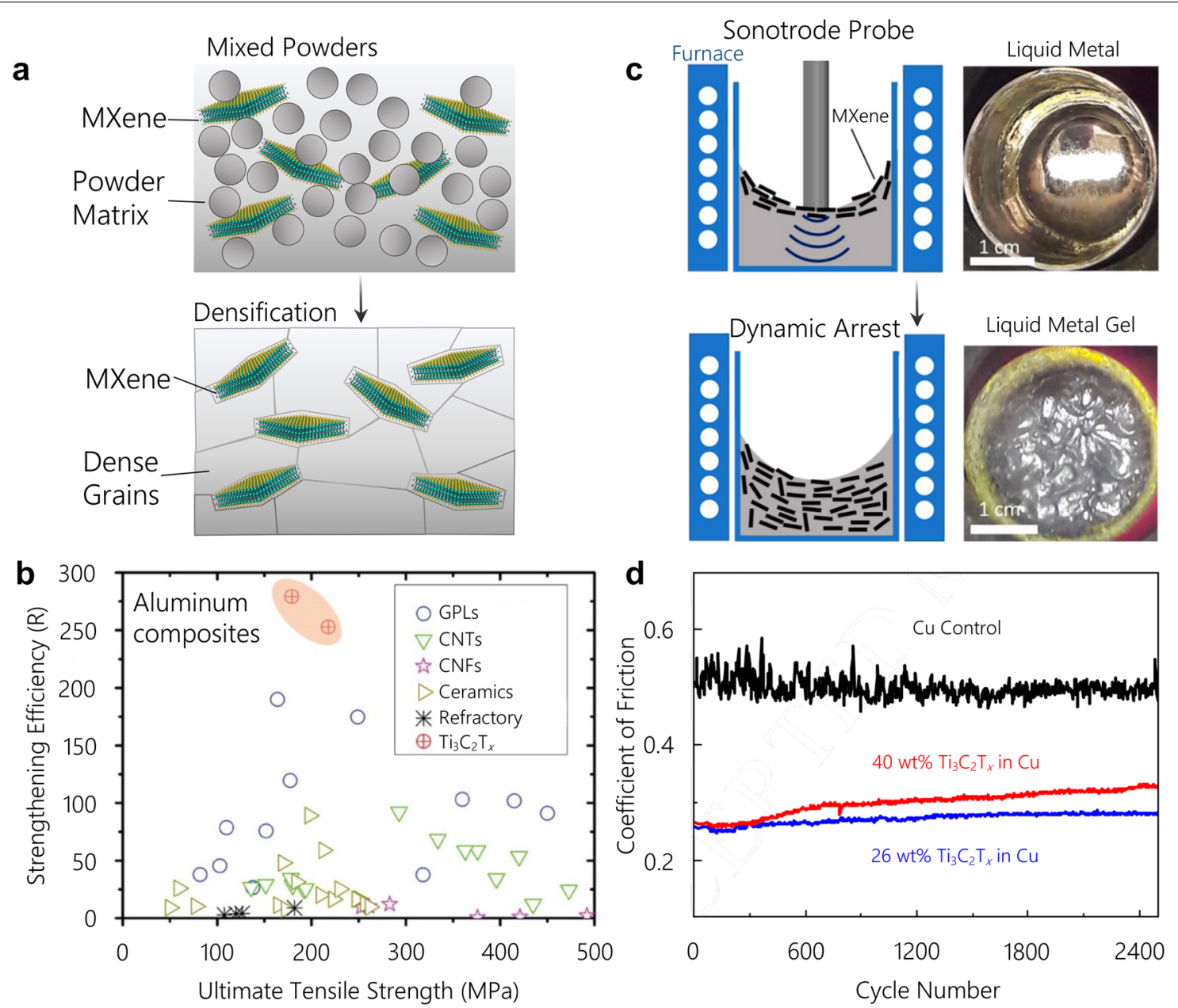

Fig. 2 MXenes metal matrix composites, processing and improved mechanical and tribological properties. a A schematic representing the MXene single-flake assembly and mixture with metal particles followed by densification to fabricate bulk metal matrix composite. b Strengthening efficiency of different nanoparticles and nanoflakes addition into Al matrices showing few-layer delaminated $\mathrm{Ti}_{3} \mathrm{C}_{2} \mathrm{~T}_{x}$ flakes can improve the tensile strength over its pure Al matrix with a lower volume fraction than that of other common nano-reinforcement materials [44]. c MXenes can also be included into lower melting point metals in their molten phase, where sonication assists the homogenous dispersion of MXene flakes into the molten metal [48]. $\mathbf{d} \mathrm{Ti}_{3} \mathrm{C}_{2} \mathrm{~T}_{x}$ MXene flakes in a Cu matrix have shown a reduction of the coefficient of friction of two times over a pure Cu matrix [49]

phases as we have observed in high-temperature annealing of $\mathrm{Ti}_{3} \mathrm{C}_{2} \mathrm{~T}_{x}$ [40]. The full attribution of this phase transformation in molten phase infiltration [48] can be elucidated with future studies of embedded MXene flakes in MMCs.

The tribological properties of MXene metal matrix composites similarly depends on the mechanical strength and inherent properties of MXenes' surface terminations. In metal matrix composites under a ball-on-plate setup with a $5 \mathrm{~N}$ load, a $\sim 2.5$ times decrease in the coefficient of friction (COF) of a $3 \mathrm{wt} \%$ non-delaminated multilayer $\mathrm{Ti}_{3} \mathrm{C}_{2} \mathrm{~T}_{x}$ reinforced $\mathrm{Al}$ composite over 300 cycles was attributed to the increased hardness and decreased plastic deformation of the $\mathrm{Ti}_{3} \mathrm{C}_{2} \mathrm{~T}_{x}$ reinforced $\mathrm{Al}$ composite over pure $\mathrm{Al}$ [42]. In a similar configuration under a
$1 \mathrm{~N}$ load, a $26 \mathrm{wt} \%$ delaminated single-flake $\mathrm{Ti}_{3} \mathrm{C}_{2} \mathrm{~T}_{x}$ in $\mathrm{Cu}$ composite fabricated by electrodeposition processes using multilayer $\mathrm{Ti}_{3} \mathrm{C}_{2} \mathrm{~T}_{x}$ and a $\mathrm{Cu}$-containing precursor illustrated 2 times decrease in the COF and a 19 times reduction in the wear rate over its pure $\mathrm{Cu}$ counterpart (Fig. 2d). These improvements in wear behavior were attributed to the formed $\mathrm{Ti}_{3} \mathrm{C}_{2} \mathrm{~T}_{x}$-tribolayer at the contact point which reduced the required shear force for motion at the interface [49]. The reduced shear force required for contact motion in this tribolayer can be attributed to the low interlayer sliding friction between terminated MXene sheets [50].

We next turn our attention to MXenes unique properties which lend significant promise for their use in metal matrix composites. First, the solution processibility and 
high negative surface charge of MXene sheets due to its surface groups $[25,35]$ provides significant potential of MXenes toward solution-based mixing methods, such as electrostatic self-assembly [44]. In addition, MXenes' status as the stiffest solution-processable 2D nanomaterial makes MXene a great candidate 2D nanomaterial for additive manufacturing and powder metallurgy mixing processes in metal matrix composites for structural applications. Similarly, the surface terminations of MXene provide an anchor point toward chemical bonding of MXene to metal matrices. For example, the effect of -O containing surface terminations on MXenes' surface has been seen in previous interfacial transmission electron microscopy (TEM) images of few-layer $\mathrm{Ti}_{3} \mathrm{C}_{2} \mathrm{~T}_{x}$ to $\mathrm{Al}$, where $\mathrm{Al}_{2} \mathrm{O}_{3}$ forms at the interface between $\mathrm{Ti}_{3} \mathrm{C}_{2} \mathrm{~T}_{x}$ and $\mathrm{Al}$ [44], which can provide a strong chemical bond for stress transfer during mechanical loading.

Although early studies on MXene metal matrix composites have mostly investigated low-temperature melting metals, which most commonly includes $\mathrm{Al}$ and $\mathrm{Mg}$, investigation of MXenes for metal composites with temperatures exceeding $700{ }^{\circ} \mathrm{C}$ will certainly have to account for phase transitions of MXenes. Previous studies on the phase transition of $\mathrm{Ti}_{3} \mathrm{C}_{2} \mathrm{~T}_{x}$ MXene in a $\mathrm{Cu}$ matrix have identified transformation of $\mathrm{Ti}_{3} \mathrm{C}_{2} \mathrm{~T}_{x}$ to $3 \mathrm{D}$ crystalline $\mathrm{TiC}_{y}$ phase beginning at $750{ }^{\circ} \mathrm{C}$ [46]. This is supported by our previous annealing studies on pure $\mathrm{Ti}_{3} \mathrm{C}_{2} \mathrm{~T}_{x}$ films, which identified similar phase transitions that start at $700{ }^{\circ} \mathrm{C}[40]$. In addition, these previous annealing studies on $\mathrm{Ti}_{3} \mathrm{C}_{2} \mathrm{~T}_{x}$ illustrate single-flake MXene films' layered morphology is kept when transformed to $3 \mathrm{D}$ crystalline $\mathrm{TiC}$ to form nanolamellar $\mathrm{TiC}_{y}$ grains at temperatures as high as $1500{ }^{\circ} \mathrm{C}$ [40]. The stability of Ti-C in metals sintered at temperatures higher than $1000{ }^{\circ} \mathrm{C}$ illustrates MXenes' potential to provide a nanolamellar transition metal carbide reinforcing material for metals with high melting points, which is stable behavior not seen for carbonaceous nanomaterials such as graphene which can turn into undesired phases at higher temperatures [51].

However, the underlying fundamental mechanisms of how MXene mechanically improves the stiffness and strength of metal matrix composites such as surfacegroup to metal bonding, dislocation motion obstruction, or by-product phase formations has yet to be thoroughly investigated. In addition, studies on the ideal morphology (non-delaminated, few-flake multilayers, or singleflake MXenes) or surface termination compositions for improved MXene metal matrix composite tribological performance may provide further insight into the behavior of MXene composites in low-friction and low-wear applications. Overall, MXene reinforcements in metal matrix composites can utilize MXenes' mechanically strong interior and conductive behavior in combination with MXenes' high-temperature stability to form metal composites applied in high-temperature applications. However, the full range of MXenes' high-temperature stability can be further explored in ceramic matrix composites.

\section{MXene ceramic matrix composites (CMCs)}

MXenes' high young's modulus, electrical conductivity, and high-temperature phase stability lend promise for their application in ceramic matrix composites (CMCs). Additionally, MXenes solution processability and high negative zeta potentials $(-32$ to $-45 \mathrm{mV})$ [52] make them great candidates for CMCs' wet or slurry-based solution processing of green bodies without particle agglomeration as seen in more conventional nano fillers [53]. Also, the negative zeta potential of as-synthesized MXenes eliminates the need for the use of conventional surfactant materials. Solution-processing of MXene CMCs is envisioned to be scalable and can potentially be integrated into existing green body mixing methodologies. MXenes negative zeta potential can be attributed to the presence of surface groups such as $-\mathrm{F},-\mathrm{Cl},-\mathrm{O}$, and $-(\mathrm{OH})$ $[54,55]$. These surface charges result in the adsorption of MXene to the oppositely charged ceramic particles due to electrostatic attraction between MXene and the ceramic grains. In addition, MXenes' extended colloidal stability in non-aqueous solvents such as alcohols as well as processability in dry powder forms can be explored for high-energy mixing strategies. Techniques such as milling, reactive bonding and chemical infiltration may be explored in addition to solution-processing $[56,57]$. The effect of dynamic surface chemistries of MXene can also be influential in sol-gel routes for the preparation of green bodies of mixed MXene CMC powders.

Preparation of MXene CMC green bodies and sintering routes for MXene-CMCs are dependent on the type of ceramic matrices which can be classified into two categories: oxides and non-oxides. For oxides, alumina and zinc oxide systems have been explored so far. Studies involving alumina as matrix have incorporated only multilayer MXene particles. For example, multilayer particles of $\mathrm{Ti}_{3} \mathrm{C}_{2} \mathrm{~T}_{x}$ were mixed with alumina via ball milling in ethanol for $20 \mathrm{~h}$. The resulting green body was sintered in air at $1500{ }^{\circ} \mathrm{C}$ for $1 \mathrm{~h}$ (Fig. 3a,b) [58]. The composite exhibited an increase in fracture toughness, bending strength, and hardness by $\sim 300 \%, \sim 150 \%$, and $\sim 300 \%$, respectively. However, the extended sintering times in an oxygen-rich environment led to MXene phase decomposition to titanium oxide, which can affect the mechanical properties of these composites.

There are methods to mitigate MXene oxidation in ceramic oxide matrices. Recently, sputtered multilayer MXene particles with Mo and Ti have been investigated 
a
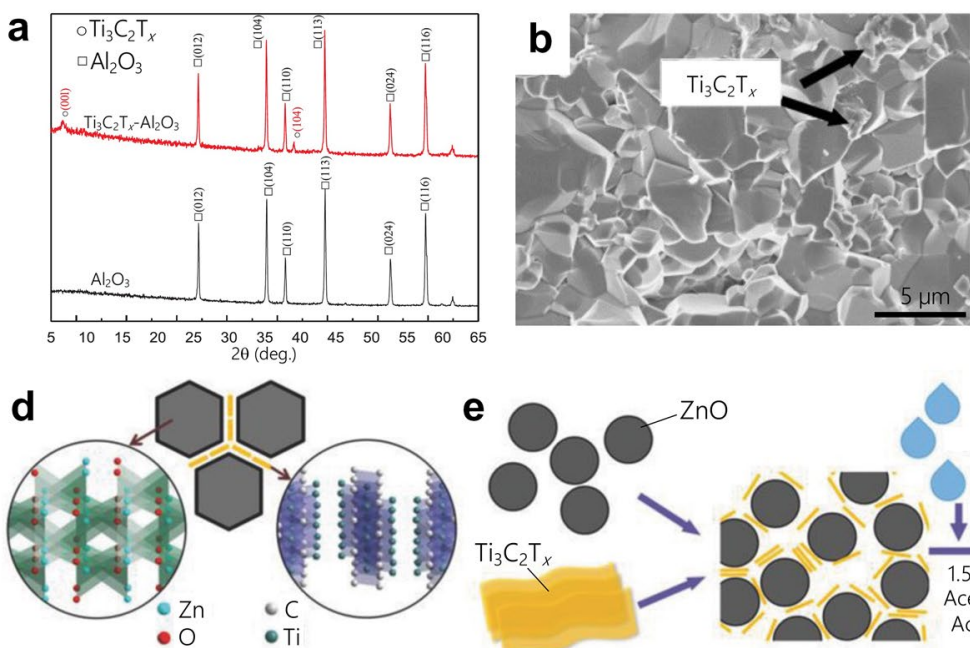

$\mathrm{ZnO}$
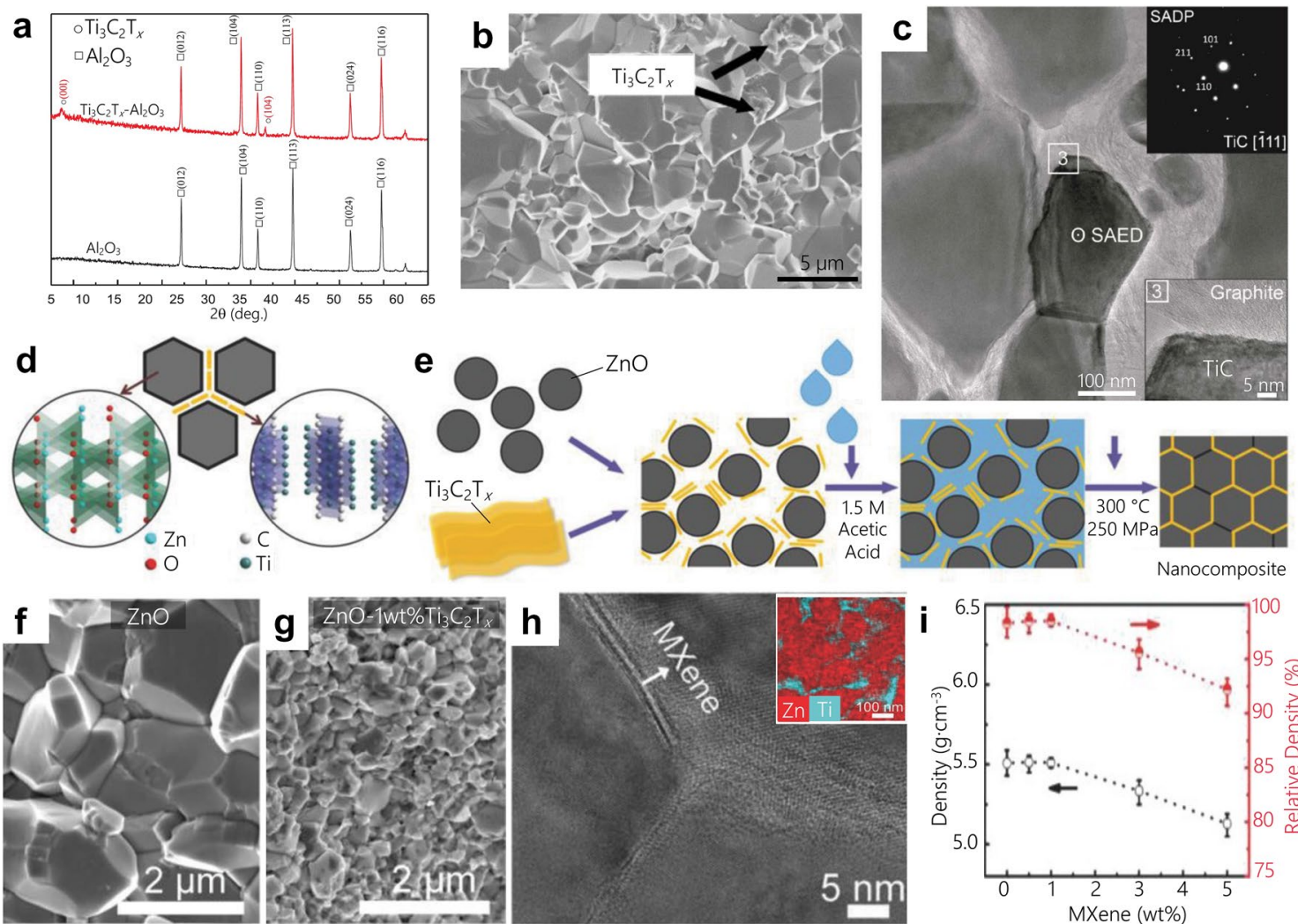

Fig. 3 MXenes ceramic matrix composites using matrices such as $\mathrm{Al}_{2} \mathrm{O}_{3}$ and $\mathrm{ZnO}$. a XRD patterns of $\mathrm{Al}_{2} \mathrm{O}_{3}$ and $\mathrm{Al}_{2} \mathrm{O}_{3}-2$ wt $\%$ Ti ${ }_{3} \mathrm{C} \mathrm{T}_{x}$ powder mixtures before sintering [58]. b SEM micrographs of $\mathrm{Al}_{2} \mathrm{O}_{3}-2$ wt $\% \mathrm{Ti}_{3} \mathrm{C}_{2} \mathrm{~T}_{x}$ composite prepared by sintering at $1500{ }^{\circ} \mathrm{C}$ [58]. $\mathbf{c}$ High-resolution TEM image of $\mathrm{Al}_{2} \mathrm{O}_{3}-2 \mathrm{wt} \% \mathrm{Ti}_{3} \mathrm{C}_{2} \mathrm{~T}_{x}$ with selected area electron diffraction (SAED) of the sintered MXene indicating TiC formation. Bottom inset shows the presence of graphitic carbon at the grain boundaries of the resulting TiC and alumina matrix [59]. $\mathbf{d}$ Schematic illustration showing (d) the grain boundary of $\mathrm{ZnO}-\mathrm{Ti}_{3} \mathrm{C}_{2} \mathrm{~T}_{x}$ nanocomposites [60] and (e) the fabrication process via cold sintering [60]. f, $\mathbf{g}$ SEM images of cols sintered pure $\mathrm{ZnO}$ and $\mathrm{ZnO}-1 \mathrm{wt} \% \mathrm{Ti}_{3} \mathrm{C}_{2} \mathrm{~T}_{x}$ composite [60]. $\mathbf{h}$ TEM image of a cold sintered $\mathrm{ZnO}-1 \mathrm{wt} \% \mathrm{Ti}_{3} \mathrm{C}_{2} \mathrm{~T}_{x}$ show the presence of $\mathrm{MXene} 2 \mathrm{D}$ flakes at $\mathrm{ZnO}$ grain boundaries. Top inset shows energy dispersive $x$-ray spectroscopy of $\mathrm{ZnO}-1 \mathrm{wt} \% \mathrm{Ti}_{3} \mathrm{C}_{2} \mathrm{~T}_{x}$ where $\mathrm{Zn}$ is shown in red and Ti is shown in cyan indicating MXenes at the grain boundaries [60]. i Densities and relative densities of $\mathrm{ZnO}-\mathrm{Ti}_{3} \mathrm{C}_{2} \mathrm{~T}_{x}$ nanocomposites cold sintered at $300{ }^{\circ} \mathrm{C}$ for $1 \mathrm{~h}$ [60]

for incorporation into alumina matrices [59]. Sputtering MXene particles with transition metals was used to create a protective shield to prevent oxidation of MXene in the oxide matrix. The sputtered MXene particles were mixed with alumina (particle size $140 \mathrm{~nm}$ ) via wet attrition milling in isopropanol. The mixture was sintered via SPS at $1400{ }^{\circ} \mathrm{C}$ with uniaxial pressure of $35 \mathrm{MPa}$ and a dwell time of $3 \mathrm{~min}$. The resulting CMCs with $0.5 \mathrm{wt} \%$ of $\mathrm{Ti}_{3} \mathrm{C}_{2} \mathrm{~T}_{x}$ exhibited an improved hardness $(10 \%)$ and fracture toughness $(15 \%)$ in comparison to monolithic alumina [59]. High-temperature $\left(1400{ }^{\circ} \mathrm{C}\right)$ composite sintering turned $\mathrm{Ti}_{3} \mathrm{C}_{2} \mathrm{~T}_{x}$ to $\mathrm{TiC}$ particles (Fig. 3c) as expected from the high-temperature phase transformation behavior of MXenes. Graphitic carbon was detected at the grain boundaries of these resulting $\mathrm{TiC}$ and alumina matrix (Fig. 3c bottom inset). The presence of carbon at the grain boundaries can be related to over etched outer surfaces of
$\mathrm{Ti}_{3} \mathrm{C}_{2} \mathrm{~T}_{x}$ particles when etched with $48 \%$ hydrofluoric acid for $24 \mathrm{~h}$ [38]. However, sintered composites with Mo-sputtered MXene particles show $\mathrm{Mo}_{2} \mathrm{C}$ at the grain boundaries indicating the reaction of Mo with graphitic carbon during the sintering process. Overall, sputtering MXenes with transition metals was shown to be an effective method to improve the oxidation resistance of MXenes specially when incorporated in oxygenrich matrices and improve the mechanical properties [59]. Further studies are needed to fully understand the effects of the metallic sputtering at the interfacial regimes between metal-MXene, metal-oxide matrices and MXene-oxide matrices.

Another method to prevent MXenes' oxidation when mixed with oxide matrices is low-temperature sintering processes. Cold-sintering has been explored for singleflake $\mathrm{Ti}_{3} \mathrm{C}_{2} \mathrm{~T}_{x}$ MXene mixture with submicron $\mathrm{ZnO}$ particles. The composite mixtures were prepared by mixing 
$\mathrm{ZnO}$ particles with 0.5 to $5 \mathrm{wt} \%$ of $\mathrm{Ti}_{3} \mathrm{C}_{2} \mathrm{~T}_{x}$ single-flake solution and sonicated for $15 \mathrm{~min}$, followed by freezedrying for $72 \mathrm{~h}$. The resulting $\mathrm{ZnO}-\mathrm{Ti}_{3} \mathrm{C}_{2} \mathrm{~T}_{x}$ powders were mixed with $\sim 20 \mathrm{wt} \%$ of $1.5 \mathrm{M}$ acetic acid (1 g of powder with $0.2 \mathrm{~g}$ of acetic acid), and the wet powders were sintered at $300{ }^{\circ} \mathrm{C}$ for $1 \mathrm{~h}$ at $250 \mathrm{MPa}$ [60]. The schematic of cold sintering method of $\mathrm{ZnO}-\mathrm{Ti}_{3} \mathrm{C}_{2} \mathrm{~T}_{x}$ composites is shown in Fig. 3d, e. Addition of MXene flakes at the grain boundaries prevented $\mathrm{ZnO}$ grain growth (compare Fig. $3 \mathrm{f}$ and $g$ ). MXenes also enhanced the electrical conductivity of $\mathrm{ZnO}$ by 5 orders of magnitude with the addition of $5 \mathrm{wt} \% \mathrm{Ti}_{3} \mathrm{C}_{2} \mathrm{~T}_{x}$. Figure $3 \mathrm{~h}$ shows the presence of MXene flakes at the grain boundaries of $\mathrm{ZnO}$, which provided an efficient pathway for the electron transport to improve the electrical conductivity of $\mathrm{ZnO}-\mathrm{Ti}_{3} \mathrm{C}_{2} \mathrm{~T}_{x} \mathrm{CMC}$ [60].

In non-oxide ceramics, $\mathrm{CMCs}$ have also taken advantage of MXenes' strong mechanical stiffness, 2D layered structure, as well as the electromagnetic interference (EMI) shielding properties. In a study, $\mathrm{Ti}_{3} \mathrm{C}_{2} \mathrm{~T}_{x}$ multilayer particles with $\mathrm{Si}_{3} \mathrm{~N}_{4}$ were ball-milled in isopropanol media for $10 \mathrm{~h}$ [61]. The green bodies were sintered via SPS at $1750{ }^{\circ} \mathrm{C}$ with a dwell time of $30 \mathrm{~min}$ and a uniaxial pressure of $30 \mathrm{MPa}$. The characterization results indicated that addition of an oxide sintering additive, such as $\mathrm{ZrO}_{2}$, was needed to achieve high densification. However, when the oxide additive was used, the sintered composite showed no indication of MXene in the final CMCs. Despite MXene transformation to oxide and formation of $\mathrm{Si}_{2} \mathrm{~N}_{2} \mathrm{O}$, the addition of $\mathrm{Ti}_{3} \mathrm{C}_{2} \mathrm{~T}_{x}$ enabled the modification of the phase composition of the ceramic by limiting the $\alpha-\mathrm{Si}_{3} \mathrm{~N}_{4} \rightarrow \beta-\mathrm{Si}_{3} \mathrm{~N}_{4}$ phase transition [61]. At $5.2 \mathrm{MPa} \mathrm{m}^{1 / 2}$, the fracture toughness of the $0.7 \mathrm{wt} \%$ $\mathrm{Ti}_{3} \mathrm{C}_{2} \mathrm{~T}_{x}-\mathrm{ZrO}_{2}-\mathrm{Si}_{3} \mathrm{~N}_{4}$ composite was measured to be $15 \%$ higher than that of a pure $\mathrm{Si}_{3} \mathrm{~N}_{4}$ sintered at similar conditions. In another study, $\mathrm{Ti}_{3} \mathrm{C}_{2} \mathrm{~T}_{x}$ MXene was mixed with a polymer (hyperbranched polyborosilazane) at 3-10 wt\% and after polymerization at $400{ }^{\circ} \mathrm{C}$ for $2 \mathrm{~h}$ followed by pyrolyzation at $1000{ }^{\circ} \mathrm{C}$ and subsequent annealing, a $\mathrm{TiC} /$ $\mathrm{SiBCN}$ ceramics were fabricated. The resulting MXenederived $\mathrm{TiC}$ reinforced $\mathrm{SiBCN}$ composite exhibited good absorption in the $\mathrm{X}$-band as well as a stable performance at higher temperatures (up to $600{ }^{\circ} \mathrm{C}$ ) in argon as well as air atmospheres [62]. Overall, the layered formation of nanocrystalline non-stoichiometric $\mathrm{TiC}_{y}$ crystals at the grain boundaries is likely the reason for the CMCs' higher thermal stability.

$\mathrm{Ti}_{2} \mathrm{CT}_{x}$ MXene was used as a filler to develop SiC composites [63]. 1 to $3 \mathrm{wt} \% \mathrm{Ti}_{2} \mathrm{CT}_{x}$ few-layer MXene flakes were solution-processed in isopropanol and mixed with $\beta$-SiC (particle size $420 \mathrm{~nm}$ ) in a planetary ball mill for $10 \mathrm{~h}$. The green bodies were then sintered via SPS in a vacuum at $1900{ }^{\circ} \mathrm{C}$ for $30 \mathrm{~min}$ with a heating rate of $50{ }^{\circ} \mathrm{C} / \mathrm{min}$ and applied uniaxial pressures of $50 \mathrm{MPa}$.
Sintered CMCs exhibited improved densification with relative densities of $99.5 \%$ in composites with $1 \mathrm{wt} \%$ $\mathrm{Ti}_{2} \mathrm{CT}_{x}$ loading when compared to pure $\mathrm{SiC}(\sim 98.5 \%)$. A nominal $10 \%$ increase in hardness and a $66 \%$ increase in fracture toughness were also reported for composites with 1 wt\% MXene content against pure SiC. MXenes' behavior as a sintering aid for obtaining densified $\mathrm{SiC}$ composites can further be expanded to study other carbide systems and their behavior with MXene as fillers.

MXene ceramic composites are in their infancy and there are limited number of studies in this field. However, since MXenes transform to bulk carbides at high temperatures [40], the wealth of knowledge on bulk 3D crystalline carbides as reinforcements in CMCs can help our understanding and expectations of MXene CMCs. In general, the addition of secondary fillers is shown to improve densification, sinterability, and enhanced oxidation stability, while preventing excessive grain growth in CMCs [64-67]. Monocarbide 3D crystalline filler phases such as $\mathrm{SiC}, \mathrm{WC}, \mathrm{VC}$ are conventionally used to improve the processing of high-temperature materials such as $\mathrm{ZrB}_{2}, \mathrm{HfB}_{2}$ ceramics [68-70]. The presence of transition metal carbide phases at the grain boundaries of the ceramic matrix has been demonstrated to improve the bending strength of the composite materials by improving intergranular bonding between ceramic grains through diffusion [71]. This intergranular bonding is due to inherent synergetic phase compatibility between carbide reinforcements and high-temperature ceramics [72]. In addition to intergranular strengthening, these carbide phases can also provide a range of advantageous material properties to CMCs due to their intrinsic mechanical and electrical properties while also improving their oxidation stabilities [73-75]. MXenes are a particularly promising carbide nano filler, as they can be considered ordered carbon vacancy carbides [40] with strong interior $\mathrm{M}-\mathrm{X}$ ionic/covalent bonding capable of forming primary bonds with ceramic matrices due to their surface groups.

\section{Future outlook of MXene as a high-temperature additive}

MXenes' inherent strength and conductivity paired with their compatibility toward solution-processibility in mixing with metal and ceramic matrices makes them a particularly strong candidate for future metal and ceramic matrix composites. In general, MXenes' status as a highly stiff solution-processable 2D nanomaterial with abundant surface groups makes MXene a strong candidate as compared to other nanomaterials that require structurally detrimental processes of mixing and densification, or additives to create surface functionalities capable of similar behavior as MXenes. 
Future studies on structural MXene metal matrix composites should take advantage of single-flake MXenes for their high surface area and available surface terminations for strong interfacial bonding for stress transfer. Furthermore, recent studies toward surface group functionalization [18] illustrate potential for tuning MXenes surface group to mediate chemical bonding of MXenes to the metal matrix, which can provide a strong interface for stress transfer in structural metal composites. In structural applications requiring the use of multilayer flakes of MXenes, studies on the wettability of MXenes with the metal matrix will be necessary to ensure the metal matrix can be partially infiltrated into the layers of MXene flakes to prevent detrimental van-der-Waals sliding interactions of the 2D flakes in the MXene particles.

In current studies on MXene metal matrix composites, their mechanical and tribological enhancement behavior thus far have indicated MXenes' ability to perform as stable additives, as shown in Fig. 4a. This impressive behavior of MXenes in low-temperature metals thus far paired with their high-temperature stability indicates their potential for high melting-point metals, as shown in Fig. 4b. The formation of lamellar carbides within highmelting point metals could potentially reap benefits from interfacial bonding between the $\mathrm{M}-\mathrm{C}$ structure and the metal mediated by surface groups, which could result in improved mechanical and tribological properties of
MXene metal matrix composites, additive manufacturing routes such as laser sintering, which is already used for other $2 \mathrm{D}$ materials $[76,77]$, can be adopted to create dense metal composites from powder mixtures of MXene and their metal matrices. MXenes own a particular promise for additive manufacturing of metal matrix composites due to their inherent solution processability and negative surface charge, which can potentially be used to create scalable solution mixed batch sizes for industrylevel additive sintering processes. Future studies on this topic should analyze the resultant mechanical properties and phase stability of MXenes during the additive manufacturing processes. These high-melting-point metalMXene composites could see use in applications where rapid thermal fluctuations are a concern to the mechanical integrity, such as aircraft turbines shown in Fig. 4c, or where low-friction is a concern, such as engine pistons as shown in Fig. 4d. However, future studies of phase transformations and reactions of MXene with metals will be necessary to characterize the phase transformations within the metal matrices.

In ceramic composites, the highly stiff and electrically conductive M-X core of MXenes lends promise for MXenes to be used as additives to improve fracture properties and electron transport in CMCs. In addition, the large amount of possible transition metal carbide or nitride combinations of MXene paired with MXenes'

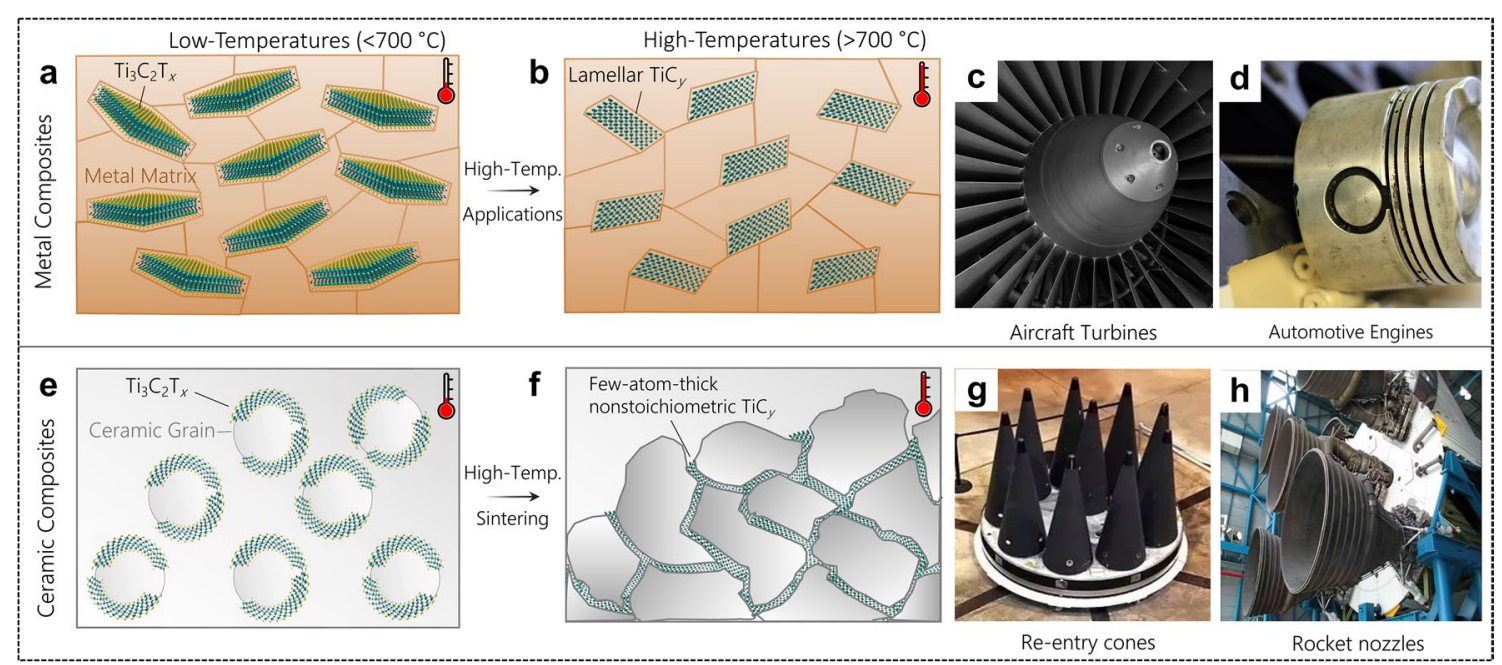

Fig. 4 Future applications of MXene metal and ceramic composites. $\mathbf{a}$, $\mathbf{b}$ MXenes can be utilized as reinforcement materials in single-flake form (a) or be converted to lamellar TiC in metals under high-temperature applications (b). c, d Some of these high-temperature applications may require strong mechanical properties such as aircraft turbines (c) or low friction applications such as automotive engine cylinders (d). e, f MXenes' 2D nature can be utilized to wrap ceramic grains (e) to undergo phase transformation to strong and conductive chemically bonded intergranular reinforcement materials (f). $\mathbf{g}, \mathbf{h}$ The application of MXenes toward strong-intergranular bonding can provide use for MXenes as ultra-high temperature ceramic materials for aerospace re-entry cones $(\mathbf{g})$ or rocket nozzles $(\mathbf{h})$. In panels $\mathbf{a}, \mathbf{b}, \mathbf{e}$, and $\mathbf{f}$ schematics, the size of MXene flakes versus the matrix grains are not proportional for the sake of visual clarity

the composite material. In future application studies of solution processibility illustrates MXenes' potential to 
be compositionally tailored for improved grain-boundary bonding in structural ceramic matrix composites. Self-assembly processes can be implemented to design and develop single MXene flake-wrapped ceramic grains with extremely low volumetric loadings of the filler, that is MXene, in the CMCs, as shown in Fig. 4e. MXenes stability and phase transformation to lamellar carbides in oxygen-free environment [40], such as boride, carbide, and nitride matrices make MXenes the only high-temperature carbide 2D nanomaterials. The high-temperature stability of MXenes can be used to develop CMCs with a greater degree of grain refinement and crack arrest behavior due to a conformal presence of MXene flakes on the ceramic matrix grains, as shown in Fig. 4f. The fundamental methods of how MXene behaves in ceramic matrix composites such as interfacial bonding, crack blunting, or synergetic chemical behavior have yet to be thoroughly investigated. Similarly, a full characterization of phase transformations at the interface of MXene to the ceramic grains during sintering has yet to be conducted.

Future prospects in the design of MXene incorporated CMCs are very promising, with many exciting properties yet to be explored and evaluated. In addition to improvement in conventional mechanical properties of CMCs, MXenes have the potential to enhance electrical, optical, and magnetic properties of materials for applications such as EMI shielding, capacitive, dielectric, and electrically conductive additives, or energy storage. MXenes may be explored as fillers in additive manufacturing strategies for CMCs. Their high solution compatibility and ability to disperse without forming agglomerates may be harnessed in developing 3D-printing strategies for micro and macrostructural engineering. Beyond regular ceramic composites, MXene's transformation to lamellar carbides opens their applications in ultra-high temperature ceramics (UHTCs) in fields such as space explorations extraterrestrial landings, and space science such as re-entry cones (Fig. 4g) or rocket nozzles (Fig. 4h). Future studies will need to investigate the mechanical behavior such as fracture, thermal stresses, and fatigue behavior in cyclical loadings of both non-phase transformed and phase transformed MXenes flakes at the UHTC grains to identify the ideal MXene compositions and structures for these applications.

\section{Conclusions}

Since their discovery in 2011, the impressive behavior of MXenes has led to their application in a large range of applications. Although recent studies have started to investigate MXene as a reinforcement material in metal and ceramic matrix composites, there still remain many possibilities for MXenes to revolutionize these composite materials which have yet to be experimentally explored. The mechanical, tribological, and electrically conductive behavior of MXenes paired with their large range of transition metal, carbon or nitrogen, and surface group compositions lends significant potential for application-based design of MXenes for metal and ceramic matrix composite applications. In addition, MXenes' highly stable transition metal carbide and nitride core at temperatures exceeding $1000{ }^{\circ} \mathrm{C}$ means that MXene is potentially the most promising reinforcing 2D nanomaterial for high-temperature applications of metal and ceramic matrix composites. We believe that the impressive potential of MXenes will result in MXenes becoming the leading nanomaterial reinforcement in composites to meet the high-temperature applications of tomorrow's metal and ceramic matrix composite materials.

\section{Acknowledgements}

The authors acknowledge startup funding from the Department of Mechanical and Energy Engineering and Purdue School of Engineering and Technology at IUPUI.

\section{Authors' contributions}

BCW and SKN contributed to this manuscript equally. All authors read and approved the final manuscript.

\section{Funding}

The authors acknowledge startup funding from the Department of Mechanical and Energy Engineering and Purdue School of Engineering and Technology at IUPUI.

\section{Availability of data and materials}

Reference to the datasets analyzed during the current study are available from the corresponding author on reasonable request.

\section{Declarations}

\section{Competing interests}

The authors declare that they have no competing interests.

\section{Author details}

${ }^{1}$ Department of Mechanical and Energy Engineering, Purdue School of Engineering and Technology, Indiana University-Purdue University Indianapolis, 46202 Indianapolis, IN, USA. ${ }^{2}$ Integrated Nanosystems Development Institute, Indiana University-Purdue University Indianapolis, IN 46202 Indianapolis, USA.

Received: 28 February 2021 Accepted: 10 May 2021

Published online: 02 June 2021

References

1. C. Lee, X Wei, J.W. Kysar, J. Hone, Measurement of the elastic properties and intrinsic strength of monolayer graphene. Science. 321, 385-388 (2008)

2. J.W. Suk, R.D. Piner, J. An, R.S. Ruoff, Mechanical properties of monolayer graphene oxide. ACS Nano 4, 6557-6564 (2010)

3. Y. Wang, J. Mao, X. Meng, L. Yu, D. Deng, X. Bao, Catalysis with two-dimensional materials confining single atoms: concept, design, and applications. Chem. Rev. 119, 1806-1854 (2019) 
4. Y. Chen, K. Yang, B. Jiang, J. Li, M. Zeng, L. Fu, Emerging two-dimensional nanomaterials for electrochemical hydrogen evolution. J. Mater. Chem. A 5, 8187-8208 (2017)

5. H. Jin, C. Guo, X. Liu, J. Liu, A. Vasileff, Y. Jiao, Y. Zheng, S.Z. Qiao, Emerging two-dimensional nanomaterials for electrocatalysis. Chem. Rev. 118, 6337-6408 (2018)

6. L. Dai, Functionalization of graphene for efficient energy conversion and storage. Acc. Chem. Res. 46, 31-42 (2012)

7. X. Peng, L. Peng, C. Wu, Y. Xie, Two dimensional nanomaterials for flexible supercapacitors. Chem. Soc. Rev. 43, 3303-3323 (2014)

8. M.F. El-Kady, Y. Shao, R.B. Kaner, Graphene for batteries, supercapacitors and beyond. Nat. Rev. Mater. 1, 16033 (2016)

9. A. Lipatov, M. Alhabeb, H. Lu, S. Zhao, M.J. Loes, N.S. Vorobeva, Y. Dall'Agnese, Y. Gao, A. Gruverman, Y. Gogotsi, A. Sinitskii, Electrical and elastic properties of individual single-layer $\mathrm{Nb}_{4} \mathrm{C}_{3} T_{x}$ MXene flakes. Adv. Electron. Mater 6, 1901382 (2020)

10. K.R.G. Lim, A.D. Handoko, S.K. Nemani, B. Wyatt, H.Y. Jiang, J. Tang, B. Anasori, Z.W. Seh. Rational design of two-dimensional transition metal carbide/nitride (MXene) hybrids and nanocomposites for catalytic energy storage and conversion. ACS. Nano. 14, 10834-10864 (2020)

11. T. Mathis, K. Maleski, A. Goad, A. Sarycheva, M. Anayee, A.C. Foucher, K. Hantanasirisakul, E. Stach, Y. Gogotsi. Modified MAX phase synthesis for environmentally stable and highly conductive $\mathrm{Ti}_{3} \mathrm{C}_{2}$ MXene. ACS Nano. 15, 6420-6429 (2021)

12. W. Hong, B.C. Wyatt, S.K. Nemani, B. Anasori, Double transition-metal MXenes: atomistic design of two-dimensional carbides and nitrides. MRS Bull. 45, 850-861 (2020)

13. M. Sokol, V. Natu, S. Kota, M.W. Barsoum, On the chemical diversity of the MAX phases. Trends Chem. 1, 210-223 (2019)

14. M. Naguib, M. Kurtoglu, V. Presser, J. Lu, J. Niu, M. Heon, L. Hultman, Y. Gogotsi, M.W. Barsoum, Two-dimensional nanocrystals produced by exfoliation of $\mathrm{Ti}_{3} \mathrm{AlC}_{2}$. Adv. Mater. 23, 4248-4253 (2011)

15. M. Ghidiu, M.R. Lukatskaya, M.Q. Zhao, Y. Gogotsi, M.B. Barsoum, Conductive two-dimensional titanium carbide 'clay' with high volumetric capacitance. Nature 516, 78-81 (2014)

16. M. Alhabeb, K. Maleski, B. Anasori, P. Lelyukh, L. Clark, S. Sin, Y. Gogotsi, Guidelines for synthesis and processing of two-dimensional titanium carbide $\left(\mathrm{Ti}_{3} \mathrm{C}_{2} \mathrm{~T}_{x}\right.$ MXene. Chem. Mater. 29, 7633-7644 (2017)

17. Y. Li, H. Shao, Z. Lin, J. Lu, L. Liu, B. Duployer, P.O.A. Persson, P. Eklund, L. Hultman, M. Li, K. Chen, X.H. Zha, S. Du, P. Rozier, Z. Chai, E. RaymundoPinero, P.L. Taberna, P. Simon, Q. Huang, A general Lewis acidic etching route for preparing MXenes with enhanced electrochemical performance in non-aqueous electrolyte. Nat. Mater. 19, 894-899 (2020)

18. V. Kamysbayev, A.S. Filatov, H. Hu, X. Rui, F. Lagunas, D. Wang, R.F. Klie, D.V. Talapin, Covalent surface modifications and superconductivity of twodimensional metal carbide MXenes. Science (2020). https://doi.org/10. 1126/science.aba8311

19. M.A. Hope, A.C. Forse, K.J. Griffith, M.R. Lukatskaya, M. Ghidiu, Y. Gogotsi, C.P. Grey, NMR reveals the surface functionalisation of $\mathrm{Ti}_{3} \mathrm{C}_{2} \mathrm{MXene.} \mathrm{Phys.}$ Chem. Chem. Phys. 18, 5099-5102 (2016)

20. M. Han, K. Maleski, C.E. Shuck, Y. Yang, J.T. Glazar, A.C. Foucher, K. Hantanasirisakul, A. Sarycheva, N.C. Frey, S.J. May, V.B. Shenoy, E.A. Stach, Y. Gogotsi. Tailoring electronic and optical properties of MXenes through forming solid solutions. J. Am. Chem. Soc. 142, 19110-19118 (2020)

21. B.C. Wyatt, A. Rosenkranz, B. Anasori, 2D MXenes: tunable mechanical and tribological properties. Adv. Mater. 33, 2007973 (2021)

22. M. Han, C.E. Shuck, R. Rakhmanov, D. Parchment, B. Anasori, C.M. Koo, G. Friedman, Y. Gogotsi, Beyond $\mathrm{Ti}_{3} \mathrm{C}_{2} \mathrm{~T}_{\mathrm{x}}$ : MXenes for electromagnetic interference shielding. ACS Nano. 14, 5008-5016 (2020)

23. M.Q. Zhao, C.E. Ren, Z. Ling, M.R. Lukatskaya, C. Zhang, K.L. Van Aken, M.W. Barsoum, Y. Gogotsi, Flexible MXene/carbon nanotube composite paper with high volumetric capacitance. Adv. Mater. 27, 339-345 (2015)

24. Q. Yang, Z. Huang, X. Li, Z. Liu, H. Li, G. Liang, D. Wang, Q. Huang, S. Zhang, S. Chen, C. Zhi, A wholly degradable, rechargeable Zn-Ti3C2 MXene capacitor with superior anti-self-discharge function. ACS Nano. 13, 8275-8283 (2019)

25. Z. Ling, C.E. Ren, M.Q. Zhao, J. Yang, J.M. Giammarco, J. Qiu, M.W. Barsoum, Y. Gogotsi, Flexible and conductive MXene films and nanocomposites with high capacitance. Proc. Natl. Acad. Sci. USA 111, 16676-16681 (2014)
26. M. Naguib, O. Mashtalir, M.R. Lukatskaya, B. Dyatkin, C. Zhang, V. Presser, Y. Gogotsi, M.W. Barsoum, One-step synthesis of nanocrystalline transition metal oxides on thin sheets of disordered graphitic carbon by oxidation of MXenes. Chem. Commun. (Camb) 50, 7420-7423 (2014)

27. C. Chen, X. Xie, B. Anasori, A. Sarycheva, T. Makaryan, M. Zhao, P. Urbankowski, L. Miao, J. Jiang, Y. Gogotsi, MoS2-on-MXene heterostructures as highly reversible anode materials for lithium-ion batteries. Angew Chem. Int. Ed. Engl. 57, 1846-1850 (2018)

28. X. Liang, Y. Rangom, C.Y. Kwok, Q. Pang, L.F. Nazar, Interwoven MXene nanosheet/carbon-nanotube composites as Li-S cathode hosts. Adv. Mater. 29, 1603040 (2017)

29. L. Zhao, B. Dong, S. Li, L. Zhou, L. Lai, Z. Wang, S. Zhao, M. Han, K. Gao, M. Lu, X. Xie, B. Chen, Z. Liu, X. Wang, H. Zhang, H. Li, J. Liu, H. Zhang, X. Huang, Interdiffusion reaction-assisted hybridization of two-dimensional metal-organic frameworks and Ti3C2Tx nanosheets for electrocatalytic oxygen evolution. ACS Nano 11, 5800-5807 (2017)

30. X. Wu, Z. Wang, M. Yu, L. Xiu, J. Qiu, Stabilizing the MXenes by carbon nanoplating for developing hierarchical nanohybrids with efficient lithium storage and hydrogen evolution capability. Adv. Mater. 29, 1607017 (2017)

31. Z. Li, Z. Zhuang, F. Lv, H. Zhu, L. Zhou, M. Luo, J. Zhu, Z. Lang, S. Feng, W. Chen, L. Mai, S. Guo, The marriage of the FeN4 moiety and MXene boosts oxygen reduction catalysis: Fe 3 d electron delocalization matters. Adv. Mater. 30, e1803220 (2018)

32. L. Yu, L. Hu, B. Anasori, Y.-T. Liu, Q. Zhu, P. Zhang, Y. Gogotsi, B. Xu, MXenebonded activated carbon as a flexible electrode for high-performance supercapacitors. ACS Energy Lett. 3, 1597-1603 (2018)

33. M. Boota, B. Anasori, C. Voigt, M.Q. Zhao, M.W. Barsoum, Y. Gogotsi, Pseudocapacitive electrodes produced by oxidant-free polymerization of pyrrole between the layers of 2D titanium carbide (MXene). Adv. Mater. 28, 1517-1522 (2016)

34. R.S. Hossein, K. Nemani. M.C. Grady, B. Anasori, M. Soroush, $\mathrm{Ti}_{3} \mathrm{C}_{2}$ MXenepolymer nanocomposites and their applications. J. Mater. Chem. A. 9, 8051-8098 (2021)

35. K. Maleski, V.N. Mochalin, Y. Gogotsi, Dispersions of two-dimensional titanium carbide MXene in organic solvents. Chem. Mater. 29, 1632-1640 (2017)

36. A. Lipatov, H. Lu, M. Alhabeb, B. Anasori, A. Gruverman, Y. Gogotsi, A Sinitskii, Elastic properties of $2 \mathrm{DTi}_{3} \mathrm{C}_{2} \mathrm{~T}_{\mathrm{x}} \mathrm{MXene}$ monolayers and bilayers. Sci. Adv. 4, 1-7 (2018)

37. J.L. Hart, K. Hantanasirisakul, A.C. Lang, B. Anasori, D. Pinto, Y. Pivak, J.T. van Omme, S.J. May, Y. Gogotsi, M.L. Taheri, Control of MXenes' electronic properties through termination and intercalation. Nat. Commun. 10, 522 (2019)

38. M. Seredych, C.E. Shuck, D. Pinto, M. Alhabeb, E. Precetti, G. Deysher, B. Anasori, N. Kurra, Y. Gogotsi, High-temperature behavior and surface chemistry of carbide MXenes studied by thermal analysis. Chem. Mater. 31, 3324-3332 (2019)

39. I. Persson, L.A. Naslund, J. Halim, M.W. Barsoum, V. Darakchieva, J. Palisaitis, J. Rosen, P.O.A. Persson, On the organization and thermal behavior of functional groups on $\mathrm{Ti}_{3} \mathrm{C}_{2}$ MXene surfaces in vacuum, 2D Materials. $\mathbf{5}$, 015002 (2018)

40. B.C. Wyatt, S.K. Nemani, K. Desai, H. Kaur, B. Zhang, B. Anasori, High-temperature stability and phase transformations of titanium carbide $\left(\mathrm{Ti}_{3} \mathrm{C}_{2} \mathrm{~T}_{x}\right)$ MXene. J. Phys. Condens. Matter. (2021). https://doi.org/10.1088/1361648 X/abe793

41. J. Zhang, N. Kong, S. Uzun, A. Levitt, S. Seyedin, P.A. Lynch, S. Qin, M. Han, W. Yang, J. Liu, X. Wang, Y. Gogotsi, J.M. Razal, Scalable manufacturing of free-standing, strong $\mathrm{Ti}_{3} \mathrm{C}_{2} \mathrm{~T}_{x} \mathrm{MX}$ ene films with outstanding conductivity. Adv. Mater. 32, 2001093 (2020)

42. J. Hu, S. Li, J. Zhang, Q. Chang, W. Yu, Y. Zhou, Mechanical properties and frictional resistance of $\mathrm{Al}$ composites reinforced with $\mathrm{Ti}_{3} \mathrm{C}_{2} \mathrm{~T}_{x} \mathrm{MXene}$. Chin. Chem. Lett. 31, 996-999 (2019)

43. J. Zhang, S. Li, S. Hu, Y. Zhou, Chemical Stability of $\mathrm{Ti}_{3} \mathrm{C}_{2}$ MXene with Al in the Temperature Range 500(-)700 degrees C, Materials, 11, 1979 (2018)

44. W. Zhou, Z. Zhou, Y. Fan, N. Nomura, Significant strengthening effect in few-layered MXene-reinforced Al matrix composites. Mater. Res. Lett. 9, 148-154 (2020)

45. H. Qing, D.U. Shi-Yu, D. Qi-Huang, C. Fan-Yan, S.I. Xiao-Yang, Preparation and property of MXene/Copper alloy composites. J. Inorg. Mater. 33, 603608 (2018) 
46. M. Li, S. Wang, Q. Wang, F. Ren, Y. Wang, Preparation, microstructure and tensile properties of two dimensional MXene reinforced copper matrix composites. Mater. Sci. Eng. A. 803, 140699 (2021)

47. S.E. Shin, H.J. Choi, J.H. Shin, D.H. Bae, Strengthening behavior of fewlayered graphene/aluminum composites. Carbon 82, 143-151 (2015)

48. V. Kamysbayev, N.M. James, A.S. Filatov, V. Srivastava, B. Anasori, H.M. Jaeger, Y. Gogotsi, D.V. Talapin, Colloidal gelation in liquid metals enables functional nanocomposites of 2D metal carbides (MXenes) and lightweight metals. ACS Nano. 13, 12415-12424 (2019)

49. Y.J. Mai, Y.G. Li, S.L. Li, L.Y. Zhang, C.S. Liu, X.H. Jie, Self-lubricating $\mathrm{Ti}_{3} \mathrm{C}_{2}$ nanosheets/copper composite coatings. J. Alloy. Compd. 770, 1-5 (2019)

50. C.J. Zhang, S. Pinilla, N. McEvoy, C.P. Cullen, B. Anasori, E. Long, S.-H. Park, A. Seral-Ascaso, A. Shmeliov, D. Krishnan, C. Morant, X. Liu, G.S. Duesberg, Y. Gogotsi, V. Nicolosi, Oxidation stability of colloidal two-dimensional titanium carbides (MXenes). Chem. Mater. 29, 4848-4856 (2017)

51. S.F. Bartolucci, J. Paras, M.A. Rafiee, J. Rafiee, S. Lee, D. Kapoor, N. Koratkar, Graphene-aluminum nanocomposites. Mater. Sci. Eng. A. 528, 7933-7937 (2011)

52. M. Naguib, R.R. Unocic, B.L. Armstrong, J. Nanda, Large-scale delamination of multi-layers transition metal carbides and carbonitrides "MXenes". Dalton Trans. 44, 9353-9358 (2015)

53. H. Porwal, S. Grasso, M. Reece, Review of graphene-ceramic matrix composites. Adv. Appl. Ceram. 112, 443 (2013)

54. B. Anasori, M.R. Lukatskaya, Y. Gogotsi, 2D metal carbides and nitrides (MXenes) for energy storage. Nat. Rev. Mater. 2, 1-17 (2017)

55. M. Naguib, V.N. Mochalin, M.W. Barsoum, Y. Gogotsi, 25th anniversary article: MXenes: a new family of two-dimensional materials. Advanced materials 26, 992-1005 (2014)

56. S. Maitra, 3 - Nanoceramic matrix composites: types, processing and applications, in: I.M. Low (Ed.) Advances in ceramic matrix composites, Woodhead Publishing, pp. 27-42 (2014)

57. D. Kopeliovich, 5 - Advances in the manufacture of ceramic matrix composites using infiltration techniques, in: I.M. Low (Ed.) Advances in ceramic matrix composites, Woodhead Publishing, pp. 79-108 (2014)

58. M. Fei, R. Lin, Y. Lu, X. Zhang, R. Bian, J. Cheng, P. Luo, C. Xu, D. Cai, MXenereinforced alumina ceramic composites. Ceram. Int. 43, 17206-17210 (2017)

59. T. Cygan, J. Wozniak, M. Petrus, A. Lachowski, W. Pawlak, B. AdamczykCieślak, A. Jastrzębska, A. Rozmysłowska-Wojciechowska, T. Wojciechowski, W. Ziemkowska, A. Olszyna, Microstructure and mechanical properties of alumina composites with addition of structurally modified 2D Ti3C2 (MXene) Phase, Materials, 14, 829 (2021)

60. J. Guo, B. Legum, B. Anasori, K. Wang, P. Lelyukh, Y. Gogotsi, C.A. Randall, Cold sintered ceramic nanocomposites of 2D MXene and zinc oxide. Adv. Mater. 30, 1801846 (2018)

61. J. Wozniak, M. Petrus, T. Cygan, A. Lachowski, B. Adamczyk-Cieślak, D. Moszczyńska, A. Jastrzębska, T. Wojciechowski, W. Ziemkowska, A. Olszyna, Influence of MXene $\left(\mathrm{Ti}_{3} \mathrm{C}_{2}\right)$ phase addition on the microstructure and mechanical properties of silicon nitride ceramics. Materials. 13, 5221 (2020)

62. J. Ding, F. Chen, J. Chen, J. Liang, J. Kong, MXene-derived TiC/SiBCN ceramics with excellent electromagnetic absorption and high-temperature resistance. J. Am. Ceram. Soc. 104, 1772-1784 (2021)
63. J. Wozniak, M. Petrus, T. Cygan, A. Jastrzębska, T. Wojciechowski, W. Ziemkowska, A. Olszyna, Silicon carbide matrix composites reinforced with two-dimensional titanium carbide-manufacturing and properties. Ceram. Int. 45, 6624-6631 (2019)

64. E. Ghasali, M. Shahedi, Asl, Microstructural development during spark plasma sintering of ZrB2-SiC-Ti composite. Ceram. Int. 44, 18078-18083 (2018)

65. X. Zhang, P. Hu, J. Han, L. Xu, S.-h. Meng, The addition of lanthanum hexaboride to zirconium diboride for improved oxidation resistance. Scripta Mater. 57, 1036-1039 (2007)

66. B. Xie, L. Ma, D. Gao, X. Lin, Y. Liu, Y. Zhang, H. Gong, Influence of SiC on phase and microstructure of ZrB2 powders synthesized via carbothermal reduction at different temperatures. Ceram. Int. 44, 8795-8799 (2018)

67. R.B. Acicbe, G. Goller, Densification behavior and mechanical properties of spark plasma-sintered $\mathrm{ZrC}-\mathrm{TiC}$ and $\mathrm{ZrC}-\mathrm{TiC}-\mathrm{CNT}$ composites. J. Mater. Sci. 48, 2388-2393 (2013)

68. D.-W. Ni, J.-X. Liu, G.-J. Zhang, Pressureless sintering of $\mathrm{HfB}_{2}-\mathrm{SiC}$ ceramics doped with WC. J. Eur. Ceram. Soc. 32, 3627-3635 (2012)

69. J.Zou, G.-J. Zhang, Y.-M. Kan, P.-L. Wang, Pressureless densification of $\mathrm{ZrB}_{2}-\mathrm{SiC}$ composites with vanadium carbide. Scripta Mater. 59, 309-312 (2008)

70. H.J. Brown-Shaklee, W.G. Fahrenholtz, G.E. Hilmas, Densification behavior and microstructure evolution of hot-pressed $\mathrm{HfB}_{2}$. J. Am. Ceram. Soc. 94, 49-58 (2011)

71. A.L. Chamberlain, W.G. Fahrenholtz, G.E. Hilmas, D.T. Ellerby, High-strength zirconium diboride-based ceramics. J. Am. Ceram. Soc. 87, 1170-1172 (2004)

72. A.I. Gusev, Phase equilibria in $M-X-X^{\prime}$ and $M-A I-X$ ternary systems $(M=$ transition metal; $\left.X, X^{\prime}=B, C, N, S i\right)$ and the crystal chemistry of ternary compounds. Russ. Chem. Rev. 65, 379-419 (1996)

73. W.S. Williams, Transition metal carbides, nitrides, and borides for electronic applications. JOM 49, 38-42 (1997)

74. W.S. Williams, Physics of transition metal carbides. Mater. Sci. Eng. A 105 $1-10(1988)$

75. G.M. Demyashev, Transition metal-based nanolamellar phases. Prog. Mater Sci. 55, 629-674 (2010)

76. D. Lin, C. Richard Liu, G.J. Cheng, Single-layer graphene oxide reinforced metal matrix composites by laser sintering: microstructure and mechanical property enhancement. Acta Mater. 80, 183-193 (2014)

77. S. Wen, K. Chen, W. Li, Y. Zhou, Q. Wei, Y. Shi, Selective laser melting of reduced graphene oxide/S136 metal matrix composites with tailored microstructures and mechanical properties, Mater. Design. 175, 107811 (2019)

\section{Publisher's Note}

Springer Nature remains neutral with regard to jurisdictional claims in published maps and institutional affiliations.

\section{Submit your manuscript to a SpringerOpen ${ }^{\circ}$ journal and benefit from:}

- Convenient online submission

- Rigorous peer review

- Open access: articles freely available online

- High visibility within the field

- Retaining the copyright to your article

Submit your next manuscript at springeropen.com 